\title{
Adolescents' pain coping profiles: Expectations for treatment, functional outcomes and adherence to psychological treatment recommendations
}

\author{
Robyn Lewis Claar PhD, Laura E Simons PhD
}

RL Claar, LE Simons. Adolescents' pain coping profiles: Expectations for treatment, functional outcomes and adherence to psychological treatment recommendations. Pain Res Manage 2011;16(3):192-196.

OBJECTIVES: To explore how adolescents' pain coping profiles relate to their expectations regarding psychological treatment recommendations, and to examine patients' functioning and engagement in psychological treatment three months following a multidisciplinary pain clinic evaluation. METHODS: Adolescents and their parents completed measures of pain coping strategies, treatment expectations, pain ratings, somatic symptoms, school absences and functional disability. Parents also reported whether patients followed through with psychological treatment recommendations. RESULTS: Adaptive copers and their parents were more likely to expect psychological treatments to be helpful; however, at follow-up, there were no significant group differences in patients' participation in psychological treatment. Patients in both groups experienced significantly lower levels of somatic symptoms and functional disability, and had fewer school absences from the initial evaluation to the follow-up.

DISCUSSION: The results of the present study identify preliminary clinical implications for the way in which practitioners in multidisciplinary pain clinics present recommendations for psychological treatment to patients and their families.

Key Words: Adolescents; Pain; Pain coping profiles; Treatment expectations

Drevious research has demonstrated that the Pain Response Inventory (PRI [1]) is useful in predicting how children's pain coping strategies influence their physical and emotional functioning. For example, nonadaptive coping strategies, which generally involve passive avoidance of the stressor and include responses such as disengagement and catastrophizing, have been associated with higher levels of pain, somatic and depressive symptoms $(1,2)$, and functional disability $(2,3)$. In contrast, adaptive coping strategies that involve efforts to accept or adapt to the stressor (including acceptance and selfencouragement) have been associated with decreases in both pain (1) and depressive symptoms (3).

In the initial validation of the PRI, structural equation modelling supported a hierarchical classification of coping strategies in which the 13 subscales loaded on three higher order factors labelled Active, Passive and Accommodative coping (1). However, Walker et al (1) noted that several subscales loaded on more than one higher order factor, suggesting that specific coping strategies may serve different functions depending on the circumstances. For example, the finding that pain catastrophizing loaded on both the Passive and Active factors is consistent with the notion that catastrophizing can function as passive disengagement or an active strategy when used in conjunction with support seeking (4). Recently, Walker et al (5) used cluster analytical techniques to identify PRI profiles that summarize the pain coping activities
Les profils d'adaptation des adolescents à la douleur : les attentes à l'égard du traitement, des issues fonctionnelles et de l'adhésion aux recommandations de subir un traitement psychologique

OBJECTIFS : Explorer de quelle manière les profils d'adaptation des adolescents à la douleur sont liés à leurs attentes au sujet des recommandations de subir un traitement psychologique et examiner le fonctionnement et l'engagement du patient dans le cadre du traitement psychologique trois mois après une évaluation en clinique multidisciplinaire de la douleur. MÉTHODOLOGIES : Les adolescents et leurs parents ont consigné des mesures de stratégies d'adaptation à la douleur, d'attentes envers les traitements, de classement de la douleur, de symptômes somatiques, d'absences scolaires et d'incapacité fonctionnelle. Les parents ont également indiqué si les patients respectaient les recommandations de subir un traitement psychologique.

RÉSULTATS : Les jeunes qui s'adaptaient bien et leurs parents étaient plus susceptibles de s'attendre que les traitements psychologiques soient utiles, mais au suivi, on ne remarquait pas de différences significatives entre les groupes pour ce qui est de la participation des patients à ce traitement. Les patients des deux groupes ont présenté des taux de symptômes somatiques et d'incapacité fonctionnelle beaucoup plus faibles et des absences scolaires moins nombreuses entre l'évaluation initiale et le suivi.

EXPOSÉ : Les résultats de la présente étude indiquent les conséquences cliniques préliminaires de la manière dont les praticiens des cliniques multidisciplinaires de la douleur présentent les recommandations de subir un traitement psychologique aux patients et à leur famille.

of patients with chronic abdominal pain (6). These profiles described distinct and meaningful patterns of coping associated with different levels of emotional and physical distress. For example, patients with more adaptive coping profiles who relied on acceptance, selfencouragement or social support seeking, experienced lower levels of depressive symptoms and disability, representing a more resilient response to pain, while patients with more nonadaptive coping profiles, who responded to pain with catastrophizing and/or activity disengagement, experienced higher levels of depression and functional disability.

Using the innovative cluster analytical technique developed by Walker et al (5), Claar et al (7) extended these analyses to a diverse pain population, successfully classifying all patients in the sample and further demonstrating the external validity of these profiles. Similar to the original chronic abdominal pain sample, Claar et al (7) found that patients characterized by nonadaptive coping profiles reported higher levels of anxiety, depression and disability than patients with more adaptive coping profiles. In addition, Claar et al noted that these pain coping profiles could provide some direction in tailoring treatment interventions. For example, a family or group intervention might be particularly effective for patients who tend to seek social support (8-10), whereas patients characterized by high levels of problem solving and distraction might benefit most from a cognitive behavioural approach to pain management that provides concrete tools such as

Division of Pain Medicine, Department of Anesthesiology, Perioperative and Pain Medicine, Children's Hospital Boston and Harvard Medical

School, Boston, Massachusetts

Correspondence: Dr Robyn Lewis Claar, Pain Treatment Service, Children's Hospital Boston, 333 Longwood Avenue, Boston, Massachusetts

02115, USA. Telephone 617-355-2296,fax 617-730-0199, e-mail robyn.claar@childrens.harvard.edu 
relaxation training, guided imagery and problem solving to cope with pain (11). However, no studies to date have examined whether patients' pain coping profiles can successfully predict their engagement in or receptiveness to psychological interventions.

With research linking pediatric patients' pain coping profiles crosssectionally with their emotional and physical functioning, we questioned whether patients' pain coping profiles would also be associated with their expectations for psychological interventions for pain management as well as their adherence to recommendations to seek psychological treatment. Although research in this area is limited, one study (12) found that children expected medication and relaxation to be significantly more helpful than any other approach for treating pediatric chronic pain, whereas parents expected surgery to be significantly less helpful. Tsao et al (12) found that, overall, children expected the benefit of complementary and alternative medical treatments to be fairly small, with parents' expectations only somewhat more positive. Patients' and parents' expectations for treatment also likely influence the degree to which they adhere to treatment recommendations; recent research (13) indicates that only one-half of patients treated in a multidisciplinary pain clinic adhered to recommendations for medication changes and initiating psychological treatment.

The current study sought to preliminarily explore how patients' coping profiles relate to patients' and parents' expectations for psychological treatment interventions; patients' emotional and physical functioning at a three-month follow-up evaluation; and patients' adherence to psychological treatment three months after evaluation in a multidisciplinary pediatric pain clinic. We hypothesized that individuals with adaptive coping profiles would have more positive expectations of the effectiveness of psychological interventions, whereas patients with nonadaptive coping profiles would report lower expectations of intervention effectiveness before their multidisciplinary clinic evaluation. We also expected that adolescents with more adaptive coping profiles would display better functioning (eg, fewer somatic symptoms, less functional disability, fewer school absences and lower pain ratings) at both the initial evaluation and at the three-month follow-up. Finally, we hypothesized that patients with adaptive coping profiles would be more likely than patients with nonadaptive coping profiles to adhere to recommendations to engage in psychological treatment three months after the pain clinic evaluation.

\section{METHODS}

\section{Participants}

Potential participants included all patients 13 to 17 years of age who underwent a multidisciplinary evaluation at a tertiary pain clinic in a large, urban northeastern pediatric hospital between March and September 2007. Of the 104 families who consented to participate, 85 provided the data necessary for the analyses. The flow of participants in the study is detailed in Figure 1.

The sample was predominantly Caucasian (91.9\%) and female $(85.7 \%)$, reflecting the composition of patients typically seen in this tertiary care clinic. The mean $( \pm$ SD) age was $14.98 \pm 1.32$ years. Pain diagnoses included musculoskeletal pain $(31.0 \%)$, neuropathic pain $(16.7 \%)$, headache $(25.0 \%)$, back pain $(19.0 \%)$, abdominal pain $(3.6 \%)$, and gynecological or genitourinary pain $(4.8 \%)$. At the time of the evaluation, patients' mean duration of pain was greater than two years (29.60 \pm 37.38 months). The majority of parents were married $(72.8 \%)$ and well educated (ie, college graduate or above: $58.1 \%$ for mothers, $60.3 \%$ for fathers). Family socioeconomic status based on the four-factor index of social status (14) ranged from 22 (semiskilled workers) to 66 (business owners or professionals), with a mean of $50.93 \pm 10.84$.

\section{Procedure}

Approval from the hospital's institutional review board was obtained before data were collected. Eligible families were recruited at the end of their evaluation in the multidisciplinary outpatient pain clinic. The study was explained in detail at that time, and written consent from parents and assent from adolescents were obtained. As part of their evaluation, patients and their parents completed self-report measures

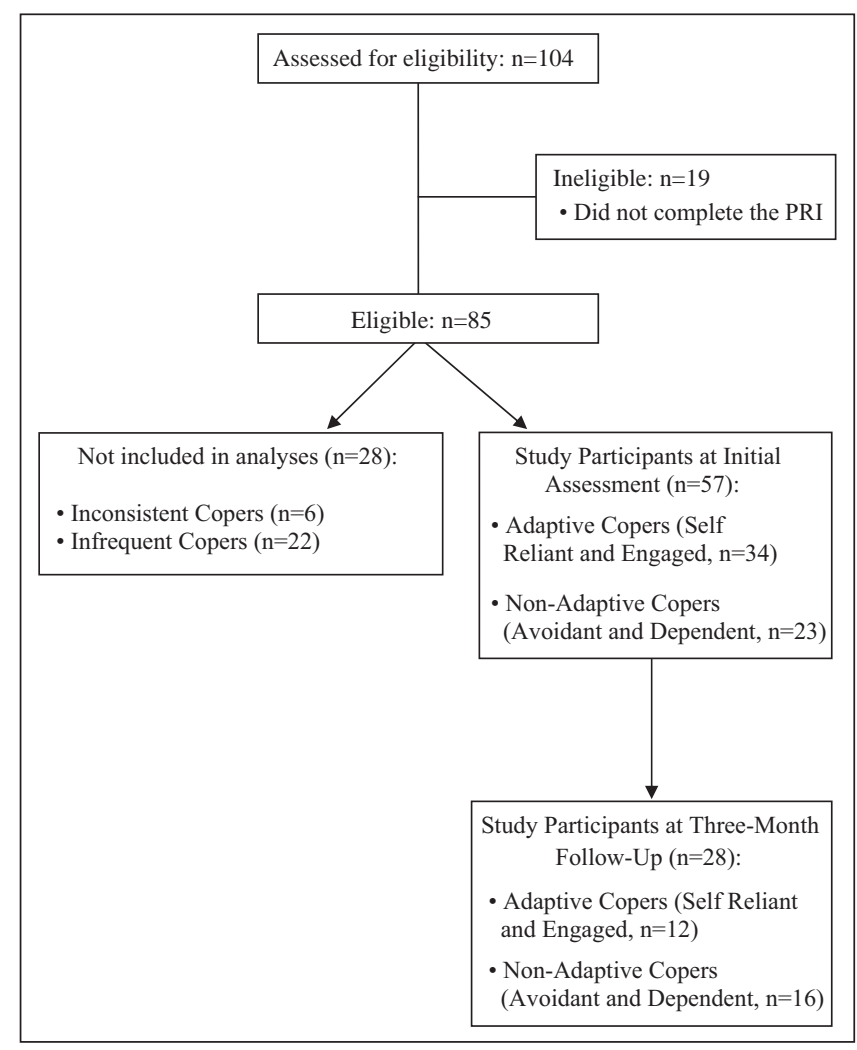

Figure 1) Flow of participants in the study. PRI Pain Response Inventory

of pain coping strategies, psychological treatment expectations, pain ratings, somatic symptoms, school absences and functional disability. During the evaluation, when psychological treatment was recommended, psychologists provided families with a list of local providers who were trained in cognitive behavioural treatment and pediatric pain management. When the information was available, the psychologists informed families whether the providers accepted their insurance. In addition, all families were educated about how to ask their insurance company about locating in-network referrals if the suggested provider did not accept their insurance.

Three months later, adolescents and their parents were telephoned by a trained research assistant for a follow-up interview. Patients again reported their pain, somatic symptoms and functional disability, while parents reported patients' school absences and whether they followed through with psychological treatment recommendations. All follow-up telephone interviews, with the parent who consented at the pain clinic evaluation and the child who assented, were conducted by a trained research assistant who was not a member of the clinical team that the families met during their initial evaluation.

\section{Measures}

Basic demographic (eg, age and sex) and medical information (eg, diagnosis) was collected from patient charts.

Pain coping strategies: The PRI (1) is a 60 -item, 13-subscale self-report questionnaire that assesses children's pain coping responses. In the present study, the two subscales specific to children with abdominal pain (condition-specific strategies and massage/guard) were eliminated from the analyses (7). The PRI has demonstrated validity and reliability. In the current study, with the exception of self-encouragement (alpha=0.67), alpha coefficient levels ranged from 0.73 to 0.92 .

Treatment expectations: The treatment expectations measure (12), completed by parents and patients, includes pediatric pain treatments that span conventional and alternative medicine. The four items most relevant to the present study's domains of interest (psychological treatment, relaxation, biofeedback and hypnosis) were examined. Each item was rated on a five-point scale from 1 (not at all helpful) 
TABLE 1

Levels of patient functioning at the initial evaluation according to coping group

\begin{tabular}{lcccc}
\hline & \multicolumn{2}{c}{ Coping type } & & \\
\cline { 2 - 4 } & $\begin{array}{c}\text { Adaptive } \\
(\mathbf{n = 2 3 )}\end{array}$ & $\begin{array}{c}\text { Nonadaptive } \\
(\mathbf{n = 3 4 )}\end{array}$ & $\mathbf{F}$ & $\mathbf{P}$ \\
\hline Current pain & $4.32 \pm 2.91$ & $4.91 \pm 3.17$ & 49 & NS \\
Pain duration & $16.36 \pm 14.44$ & $32.97 \pm 38.72$ & 3.05 & 0.09 \\
Functional disability & $31.82 \pm 11.45$ & $38.86 \pm 11.38$ & 5.04 & 0.03 \\
Somatic symptoms & $24.48 \pm 14.79$ & $31.41 \pm 15.90$ & 2.65 & NS \\
School absences & $18.45 \pm 32.09$ & $18.67 \pm 19.44$ & 0.001 & NS \\
\hline
\end{tabular}

Data presented as mean \pm SD. NS Nonsignificant

to 5 (completely helpful). Because all responses were examined at the item level, no statistical reliability analyses were conducted.

Pain intensity: Patients provided their current pain rating on a standard 11-point numerical rating scale (15) from 0 (no pain) to 10 (most pain possible).

Somatic symptoms: The Children's Somatization Inventory ([16,17]) was used to assess the severity of 35 somatic symptoms during the previous two weeks. The Children's Somatization Inventory has adequate reliability and validity (16). Alpha reliability for the current sample was 0.86 at the initial assessment and 0.91 at follow-up.

Functional disability: The Functional Disability Inventory ([18,19]) was used to assess children's self-reported activity limitations in the previous two weeks due to physical health. The Functional Disability Inventory has demonstrated reliability and validity $(17,18)$; alpha reliability for the current sample was 0.89 at the initial assessment and 0.90 at the follow-up assessment.

Treatment recommendations: As part of the standard multidisciplinary evaluation, psychologists completed a clinic recommendation checklist provided to patients at the end of the multidisciplinary evaluation. The checklist included a list of the patient's recommendations from each of the three disciplines, including medical (eg, addition of new medication or additional medical testing), psychological (eg, cognitive behavioural treatment or pain coping intervention) and physical therapy (eg, begin physical therapy or use transcutaneous electrical nerve stimulation units) recommendations. Because patients' experiences with psychological treatment were the primary interest of the present study, only psychological treatment recommendations were included. The study coded whether patients were recommended a pain coping intervention (yes/no) or cognitive behavioural treatment (yes/no).

Adherence: Patient adherence to psychological treatment recommendations was assessed at follow-up using the Adherence Telephone Interview Form (20). Parents were asked whether they pursued psychological treatment for their child. The present study focused specifically on adherence to psychological treatment recommendations rather than adherence to medication and/or physical therapy recommendations because these recommendations were of most interest.

Patients were considered to be 'fully adherent' if they completed the recommendation or were currently engaged in the recommended treatment (eg, currently receiving cognitive behavioural treatment). Patients were considered to be 'nonadherent' if they did not complete the recommendation. Patients who initially pursued the recommended treatment but then discontinued, or who tried to initiate treatment but did not successfully do so (eg, treatment not covered by insurance) were considered to be 'partially adherent' (fully adherent $=1$, partially adherent $=0.50$, nonadherent $=0$ ).

School absences: Parents reported the number of school absences in the previous three months, both at the time of the evaluation and during the follow-up interview. When relevant, summer months were taken into account when calculating the number of absences (ie, number of absences was prorated by number of school days). Parentreported school absences have been found to be reliably consistent with actual school records of absences (21).
TABLE 2

Treatment expectation scores according to coping group

\begin{tabular}{|c|c|c|c|c|}
\hline & \multicolumn{2}{|c|}{ Coping group } & \multirow[b]{2}{*}{$\mathbf{F}$} & \multirow[b]{2}{*}{$\mathbf{P}$} \\
\hline & $\begin{array}{l}\text { Adapative } \\
(n=23)\end{array}$ & $\begin{array}{c}\text { Nonadaptive } \\
(n=34)\end{array}$ & & \\
\hline \multicolumn{5}{|l|}{ Parent report } \\
\hline Psychological treatment & $3.82 \pm 1.01$ & $3.11 \pm 1.08$ & 5.82 & 0.02 \\
\hline Relaxation & $3.05 \pm 1.07$ & $2.66 \pm 0.94$ & 1.97 & NS \\
\hline Hypnosis & $4.28 \pm 0.96$ & $3.73 \pm 1.05$ & 3.23 & 0.08 \\
\hline Biofeedback & $3.53 \pm 1.23$ & $3.23 \pm 1.18$ & 0.64 & NS \\
\hline \multicolumn{5}{|l|}{ Child report } \\
\hline Psychological treatment & $4.73 \pm 0.63$ & $4.02 \pm 1.19$ & 6.56 & 0.01 \\
\hline Relaxation & $3.76 \pm 1.37$ & $3.48 \pm 0.85$ & 0.81 & NS \\
\hline Hypnosis & $4.45 \pm 1.01$ & $4.50 \pm 0.88$ & 0.03 & NS \\
\hline Biofeedback & $4.37 \pm 1.12$ & $4.29 \pm 1.08$ & 0.05 & NS \\
\hline
\end{tabular}

Data presented as mean $\pm S D$. NS Nonsignificant

\section{RESULTS}

Data analysis plan and preliminary analyses

Data were analyzed using SPSS version 16.0 (IBM Corporation, USA) for Windows (Microsoft Corporation, USA). Using the PRI classification algorithm developed by Walker et al (5), participants' coping profiles were classified using cluster analysis. (Refer to Walker et al [5] for a complete description of the statistical procedures used. The algorithm used in the study can be used by other studies using the PRI; SPSS syntax is available from Dr Walker.) All 85 patients in the study were successfully classified into the coping profiles derived by Walker et al. The present sample included 17 self-reliant copers, six engaged copers, 10 avoidant copers, 24 dependent copers, 22 infrequent copers and six inconsistent copers. Due to the small sample sizes in each coping profile, the sample was further aggregated into adaptive copers (self-reliant and engaged copers $[\mathrm{n}=23]$ ) and nonadaptive copers (avoidant and dependent copers $[n=34]$ ). The groups were based on findings from Walker et al that self-reliant and engaged copers display more adaptive functioning (reporting lower levels of anxiety, distress and functional disability), while avoidant and dependent copers tend to be less adaptive (reporting high levels of emotional distress, somatic symptoms and disability). Infrequent and inconsistent copers $(n=28)$ were not examined further because previous research using these coping profiles has not yielded any significant clinical findings $(5,7)$. Refer to Figure 1 for additional information regarding participant inclusion.

Group differences were analyzed with a series of one-way ANOVAs. A $\chi^{2}$ analysis was used to examine patients' follow-up with psychological treatment recommendations. Preliminary analyses revealed that all patients were coded dichotomously as 'adherent' or 'nonadherent' to psychological treatment recommendations.

Functioning at the initial evaluation according to coping profile As predicted, nonadaptive copers reported significantly more disability at the initial evaluation than adaptive copers (Table 1). Surprisingly, there were no significant group differences between nonadaptive and adaptive copers in reports of somatic symptoms, current pain intensity, pain duration or school absences.

Treatment expectations according to coping profile

The present study also examined whether there were differences in adolescents' and parents' treatment expectations as a function of patients' pain coping profiles (Table 2). Parents of adaptive copers were more likely than parents of nonadaptive copers to expect that psychological treatment and hypnosis would be helpful. There were no group differences in parents' expectations regarding the effectiveness of other interventions including relaxation training and biofeedback. Similar to their parents, adaptive copers were more likely than nonadaptive copers to expect psychological treatment to be helpful. There were no group differences in patients' expectations regarding the effectiveness of relaxation, hypnosis or biofeedback. 


\section{Functioning at follow-up according to coping profile}

Among the 57 families who completed the PRI at the initial assessment and were classified as adaptive or nonadaptive copers, 28 parent-child dyads $(49.1 \%)$ participated in follow-up interviews. Reasons for nonparticipation/inclusion were the following: directly declined (eg, were too busy $[\mathrm{n}=10]$ ); passively declined (ie, did not answer call after repeated attempts $[n=9])$; phone disconnected $(n=2)$; and in eight families, only the parents agreed to participate in the follow-up interview. There were no significant differences between parent-child dyads who completed follow-up interviews and those who did not on parent marital status, pain duration, current pain, functional disability or somatic symptoms at the initial evaluation. However, boys were significantly less likely to participate in the follow-up; only one of nine boys participated $\left(\chi^{2}=6.49, \mathrm{P}=0.01\right)$. In addition, there was a statistically significant age difference between patients who participated in follow-up (mean age $14.69 \pm 1.36$ years) and patients who did not (mean age $15.43 \pm 12.9$ years; $\mathrm{t}[55]=2.10, \mathrm{P}<0.05)$; however, this age difference was not likely clinically meaningful.

Contrary to our expectations, there were no significant differences at follow-up between adaptive copers and nonadaptive copers in their reports of somatic symptoms (mean $16.79 \pm 15.21$ versus $20.31 \pm 17.92$, respectively; $F[1,26]=0.30$, P value nonsignificant) or functional disability (mean 29.04 \pm 11.72 versus $27.38 \pm 12.59$, respectively; $F[1,26]=0.13$, $\mathrm{P}$ value nonsignificant). Similarly, there were no significant differences between adaptive and nonadaptive copers in their report of pain at follow-up (mean $4.88 \pm 2.60$ versus $4.38 \pm 3.48 ; F[1,26]=0.17$, P value nonsignificant). However, patients in both groups had improved significantly at follow-up. For example, nonadaptive copers reported significantly fewer somatic symptoms at follow-up (mean $20.31 \pm 17.92$ ) than at the initial evaluation (mean $34.53 \pm 15.40 ; \mathrm{t}[15]=4.42, \mathrm{P}<0.001$ ). The same is true for adaptive copers (mean 16.79 \pm 15.21 versus $24.88 \pm 18.34 ; \mathrm{t}[11]=3.60$, $\mathrm{P}<0.01$ ). Nonadaptive copers also reported significantly lower levels of disability at follow-up (mean 27.38 \pm 12.59 ) compared with the initial evaluation (mean 37.75 $\pm 13.50 ; \mathrm{t}[15]=2.89, \mathrm{P}<0.01$ ). However, adaptive copers' reports of disability were not significantly different between the initial evaluation (mean 31.33 \pm 12.50 ) and follow-up (mean 29.05 \pm 11.72 ; $\mathrm{t}[12]=1.51, \mathrm{P}$ value nonsignificant). As expected, adaptive copers had

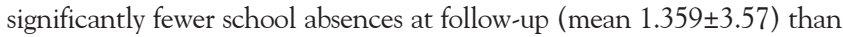
nonadaptive copers (mean 10.04 $\pm 9.39 ; \mathrm{F}[1,21]=7.84, \mathrm{P}<0.01$ ).

\section{Adherence to psychological treatment according to coping profile} At the initial evaluation, the majority of patients were recommended to pursue psychological treatment (73 of 84 [90.1\%]). In particular, a pain coping intervention was recommended to approximately one-half of the patients (44 of 84 [53.7\%]), while cognitive behavioural treatment was recommended to approximately one-third of the sample (27 of 84 [32.9\%]).

Contrary to the expectations for the present study, no group differences were found between patients who followed through with recommendations for psychological treatment (including cognitive behavioural treatment and/or a pain coping intervention) and those who did not $\left(\chi^{2}=1.20, \mathrm{P}\right.$ value nonsignificant). Approximately one-half of the patients in each group (nine of 16 nonadaptive and seven of 12 adaptive) were participating in psychological interventions at the three-month follow-up assessment.

\section{DISCUSSION}

The present study provided preliminary data on the potential usefulness of patients' pain coping profiles in understanding their expectations for pain treatment interventions, functional outcomes over time and pursuit of psychological interventions. Partially consistent with our hypotheses, we found that adaptive copers and their parents had significantly higher expectations for the effectiveness of psychological treatment than nonadaptive copers and their parents. These findings suggest that adaptive copers and their parents may be more receptive to a variety of pain treatment interventions when presenting for a multidisciplinary pain clinic evaluation, whereas nonadaptive copers may need more convincing of the potential merits of these treatments.
In contrast to previous research $(5,7)$, we did not find group differences between adaptive and nonadaptive copers in their baseline report of somatic symptoms or pain intensity. However, the current study had fewer participants and, therefore, may have lacked the statistical power to determine these differences. Contrary to our expectations, we also did not find significant group differences in patients' symptoms and functioning at follow-up; however, patients in both groups experienced significantly lower levels of somatic symptoms and functional disability, and had fewer school absences from the initial evaluation to the three-month follow-up. Finally, when examining follow-up with psychological treatment, no overall group differences emerged because approximately one-half of the patients in each coping group were participating in psychological treatments.

The present study has clear limitations. First, our three-month follow-up period may not have been sufficiently long for some families to follow through with recommendations for psychological treatment because these treatments may have been regarded as lower in priority or tried only when other interventions failed. However, we took multiple steps to promote families' completion of psychological treatment including providing all families with the names and contact information of local psychologists in their home community who specialize in treating pediatric chronic pain and educating them about how to locate in-network referrals if the recommended provider did not accept their insurance. In addition, all recommendations to pursue psychological treatment were presented in multidisciplinary feedback sessions with physicians who also emphasized their importance and usefulness.

The high attrition rate of participants in the follow-up study is another study limitation, and it is possible that patients who chose not to participate did not improve or had sought care elsewhere. Due to the small sample size, the power of testing between-group differences was diminished, particularly in the follow-up sample. However, despite this reduction in power, some significant group differences emerged, namely that although adaptive copers and their parents had more positive expectations regarding psychological treatment, approximately one-half of patients in both groups followed through with psychological treatment. Thus, despite their initial hesitation and lower expectations about these treatments, patients with nonadaptive coping styles may be open to pursuing psychological interventions if framed appropriately within a multidisciplinary setting.

The results of the present study provide several avenues for future direction including replication with a larger sample size to examine individual coping profiles - rather than aggregated profile groups - more closely. In addition, including more male participants and patients with more diverse ethnic backgrounds in future research is warranted. Future studies that also examine physicians' global ratings of improvement would further inform the usefulness of the patients' pain coping profiles in predicting their functioning over time. Finally, examination of the stability of patients' coping profiles over time would be interesting because it is possible that patients who participate in psychological treatments that alter their cognitive appraisals and pain coping techniques will display changes in their coping profiles after intervention.

The present study's results may have clinical implications for the way in which practitioners in multidisciplinary pain clinics present their recommendations to patients and their families. For example, given that adaptive copers and their parents expect that psychological interventions may be beneficial, practitioners may be able to easily make recommendations for psychological follow-up with little patient or parent resistance. In contrast, recommendations to nonadaptive copers, who have less positive expectations, may require additional explanation and persuasion; however, these patients may be equally likely to follow through with psychological treatment recommendations provided as part of a multidisciplinary evaluation.

ACKNOWLEDGEMENTS: The authors thank the Pain Treatment Service at Children's Hospital Boston (Boston, Massachusetts, USA) and its patients and families for their roles in this research, as well as the Sara Page Mayo Endowment for Pediatric Pain Research and Treatment. 


\section{REFERENCES}

1. Walker LS, Smith CA, Garber J, et al. Development and validation of the Pain Response Inventory for children. Psychol Assess 1997;9:392-405.

2. Kaminsky L, Robertson M, Dewey D. Psychological correlates of depression in children with recurrent abdominal pain. J Ped Psychol 2006;31:956-66.

3. Walker LS, Smith CA, Garber J, et al. Testing a model of pain appraisal and coping in children with chronic abdominal pain. Health Psychol 2005;24:364-74.

4. Sullivan MJL, Thorn B, Haythornthwaite JA, et al. Theoretical perspective on the relation between catastrophizing and pain. Clin J Pain 2001;17:52-64.

5. Walker LS, Baber KF, Garber J, et al. A typology of pain coping in pediatric patients with chronic abdominal pain. Pain 2008;137:266-75

6. Smith CA, Wallston KA. An analysis of coping profiles and adjustment in persons with rheumatoid arthritis. Anxiety Stress Coping 1996;9:107-22.

7. Claar RL, Baber KF, Simons LE, et al. Pain coping profiles in adolescents with chronic pain. Pain 2008;140:368-75.

8. Barry J, von Baeyer CL. Brief cognitive-behavioral group treatment for children's headache. Clin J Pain 1997;13:215-20.

9. Robins PM, Smith SM, Glutting JJ, et al. A randomized controlled trial of a cognitive-behavioral family intervention for pediatric recurrent abdominal pain. J Pediatr Psychol 2005;30:397-408.

10. Sanders M, Shepherd R, Cleghorn G, et al. The treatment of recurrent abdominal pain in children: A controlled comparison of cognitive-behavioral family intervention and standard pediatric care. J Consult Clin Psychol 1994;62:306-14.

11. Kashikar-Zuck S. Treatment of children with unexplained chronic pain. Lancet 2006;367:380-2.
12. Tsao JC, Meldrum M, Bursch B, et al. Treatment expectations for CAM interventions in pediatric chronic pain patients and their parents. Evid Based Complem Alt Med 2005;2:521-7.

13. Simons LE, Logan DE, Chastain L, Cerullo M. Engagement in multidisciplinary interventions for pediatric chronic pain: Parental expectations, barriers, and child outcomes. Clin J Pain 2010;26:291-9.

14. Hollingshead AB. Four factor index of social status. Working paper, Department of Sociology, New Haven: Yale University, 1975.

15. von Baeyer CL, Spagrud LJ, McCormick J, et al. Three new datasets supporting use of the Numerical Rating Scale (NRS-11) for children's self-reports of pain intensity. Pain 2009;143:223-7.

16. Garber J, Walker LS, Zeman J. Somatization symptoms in a community sample of children and adolescents: Further validation of the Children's Somatization Inventory. Psychol Assess 1991;3:588-95.

17. Walker LS, Garber J, Greene JW. Somatization symptoms in pediatric abdominal pain patients: Relation to chronicity of abdominal pain and parent somatization. J Abnorm Child Psychol 1991;19:379-94.

18. Claar RL, Walker LS. Functional assessment of pediatric pain patients: Psychometric properties of the Functional Disability Inventory. Pain 2006;121:77-84.

19. Walker LS, Greene JW. The Functional Disability Inventory: Measuring a neglected dimension of child health status. J Ped Psychol 1991;16:39-58.

20. MacNaughton KL, Rodrigue JR. Predicting adherence to recommendations by parents of clinic-referred children. J Consult Clin Psychol 2001;69:262-70.

21. Logan DE, Simons LE, Stein MJ, Chastain L. School impairment in adolescents with chronic pain. J Pain 2008;9:407-16. 


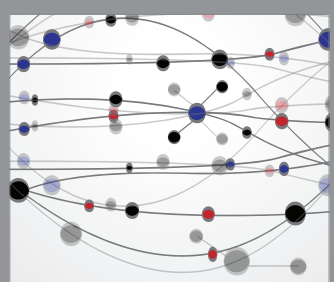

The Scientific World Journal
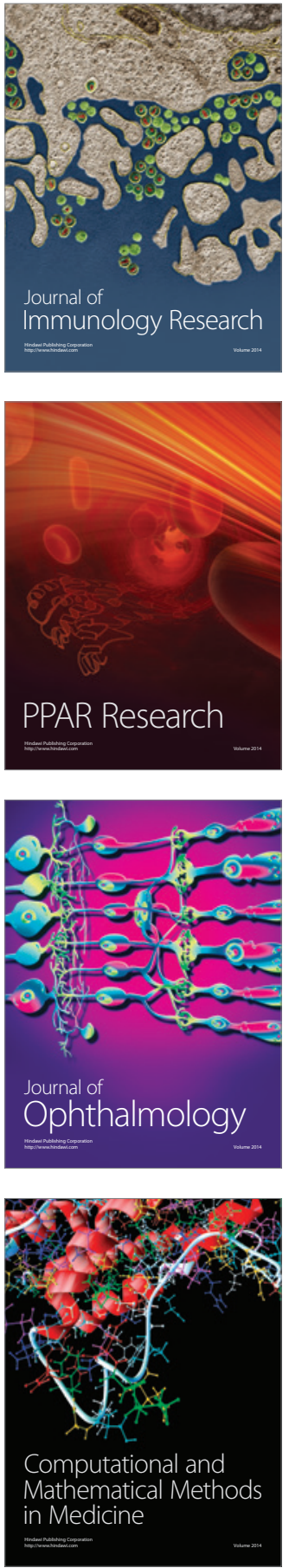

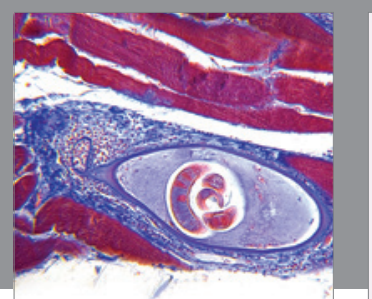

Gastroenterology Research and Practice

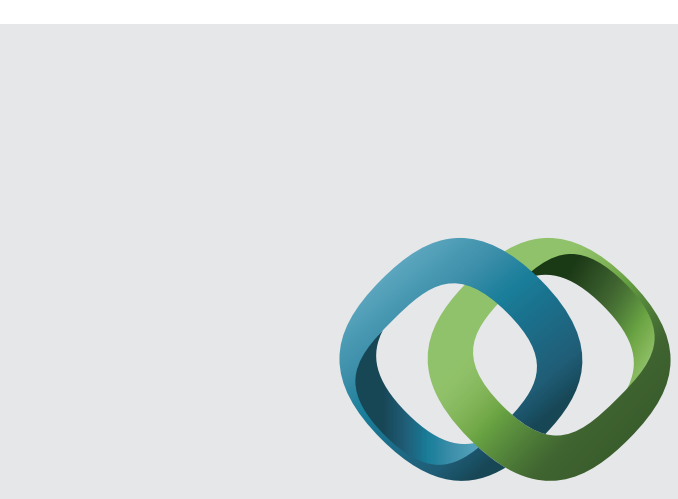

\section{Hindawi}

Submit your manuscripts at

http://www.hindawi.com
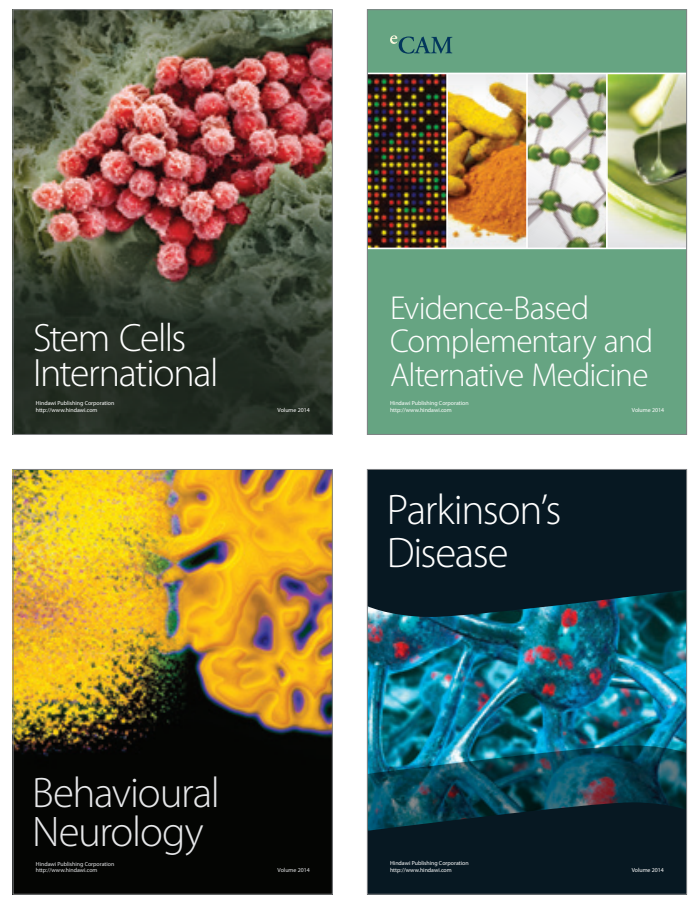
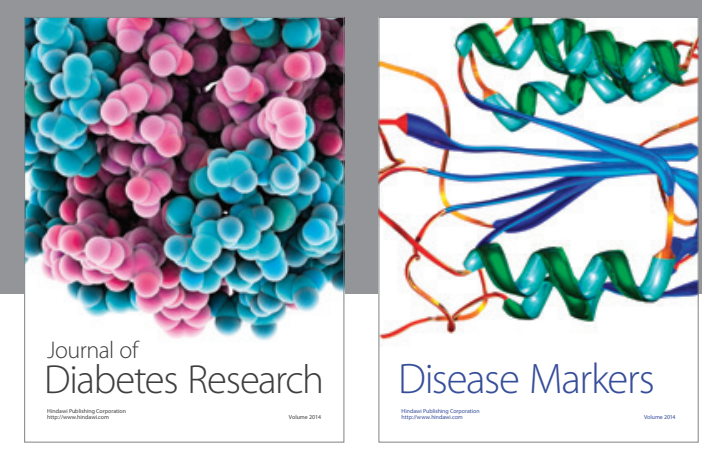

Disease Markers
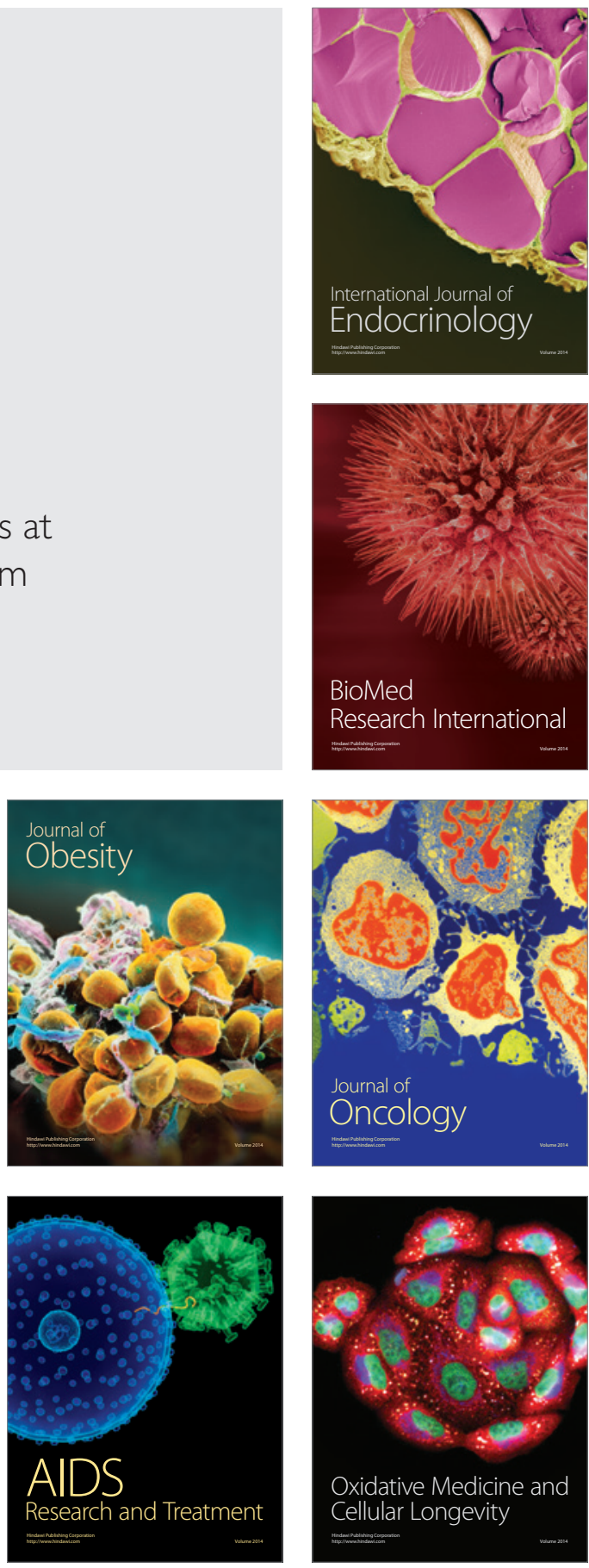